\title{
Jain point: an alternate laparoscopic non-umbilical first blind entry port to avoid vessel, viscera, adhesions and bowel (VVAB)
}

\author{
Nutan Jain ${ }^{1,2} \cdot$ Vandana Jain $^{2,3} \cdot$ Anadeep Chandi ${ }^{2,4,5} \cdot$ Sakshi Srivastava $^{2,6,7} \cdot$ Shalini Singh $^{2,8,9,10} \cdot$ N. Vasundhara $^{2,11,12}$
}

Received: 2 April 2021 / Accepted: 20 May 2021 / Published online: 13 June 2021

(c) The Author(s) 2021

\begin{abstract}
The Jain point entry is based on the concept of non-umbilical entry to avoid sudden catastrophic injury to major retroperitoneal vessels, viscera, adhesions and bowel which could happen before the start of procedure by blind umbilical entry. To study the safety and efficacy of a novel first non-umbilical blind entry port. Tertiary referral centre for advanced laparoscopic surgeries with active training and fellowship programs. A large retrospective study of 7802 cases done at Vardhman Infertility \& Laparoscopy Centre from January 2011 to December 2020. In all cases, first blind entry was by veress needle and $5 \mathrm{~mm}$ trocar and telescope through a non-umbilical port, The Jain point, irrespective of BMI, large masses, lax abdomen, previous surgery and complex situations. Patients' demographic profile, types of surgeries performed and entry-related complications were recorded and analysed. Mean age of patients was 33 years with BMI ranging from 12.66 to $54.41 \mathrm{~kg} / \mathrm{m}^{2}$. Thus, Jain point can be applicable for all ranges of BMI, all types of surgeries from simple to complex and large masses. Entry related minor complications were in $3.4 \%$ cases while major complication involving bowel occurred in one case. No case of injury to major retro-peritoneal vessel was seen. Jain point entry is a novel, first blind $5 \mathrm{~mm}$ non-umbilical, entry technique in a variety of surgeries and previous scars and patients with wide range of BMI. It has a short learning curve and continues as main ergonomic working port.
\end{abstract}

Keywords Palmer's point $\cdot$ Jain point $\cdot$ Left lateral port $\cdot$ Non-umbilical entry $\cdot$ Laparoscopic entry port $\cdot$ Entry in previous abdominal surgeries

Nutan Jain

jainnutan@gmail.com

http://www.vardhmanhospital.com

Vandana Jain

vandana.mamc03@gmail.com

Anadeep Chandi

ana.chandi@gmail.com

Sakshi Srivastava

sakshi857@icloud.com

Shalini Singh

shalinisinghobgy@gmail.com

N. Vasundhara

vasundharanagavolu@gmail.com

1 Department of Obstetrics and Gynecology, GSVM Medical College, Affiliated By Kanpur University, Kanpur, India

2 Vardhman Trauma and Laparoscopy Centre Pvt. Ltd, 3rd KM, Jansath Road, Muzaffarnagar 251001, Uttar Pradesh, India

3 Department of Obstetrics and Gynecology, Kasturba Hospital, Affiliated By Delhi University, New Delhi, India
4 Pandit Bhagwat Dayal Sharma Post Graduate Institute of Medical Sciences, Rohtak, India

5 House No: 957, sector 25, Panchkula 134109, Haryana, India

6 Rohilkhand Medical College and Hospital, Affiliated By Bareilly International University, Bareilly, India

7 House no. 341, Chhoti Baradari Part 1, Garha Road, Jalandhar 144001, Punjab, India

8 Institute of Medical Sciences, Affiliated By Banaras Hindu University, Varanasi, India

9 GBH American Hospital, Udaipur, India

10 7/571 Vikas Nagar, Aliganj, Lucknow, India

11 MCH Gynaecological Oncology, Acharya Harihar PG Institute of Cancer, Affiliated By Utkal University, Cuttack, India

12 THARA-53, Thekkemadom Road, Thrissur 680001, Kerala, India 


\section{Introduction}

The aim of this study is to introduce the concept of nonumbilical entry [1] to avoid catastrophic complications which could be associated with first blind umbilical entry [2]. Since last 70 years, the umbilicus is used as the preferred site for creating pneumoperitoneum and entering into abdominal cavity. However, the close proximity to the great vessels [3] in midline and possibility of unanticipated paraumbilical adhesion $[4,5]$ are the main drawbacks for blind umbilical entry. A large multicentric prospective study revealed [6] that the intestinal injuries and major complications during laparoscopy occur in 5.7/1000 procedures. Approximately $70 \%$ of these are related to the primary port entry. The overall incidence of laparoscopic entry injuries is 3.3/1000 with gastrointestinal damage occurring in 1.3/1000 and major vessel injuries in $1.05 / 1000$. At least $50 \%$ of the major complications occur prior to commencement of the intended surgery meaning that they are related to first blind primary umbilical port. Hence Royal College of Obstetricians and Gynaecologists (RCOG) also opinioned that umbilicus may not be the safest point for first blind entry [7]. The non-umbilical entry has been strongly advocated by a recent article entitled 'overview of gynaecological laparoscopic surgery and non-umbilical entry site' on "UpToDate" [1]. It recommends non-umbilical entry in previous surgery, large pelvic masses, gross obesity or underweight patients, pregnancy, very lax abdomen, and umbilical hernia. Looking at these recent guidelines, we fall in safe zone using the non-umbilical entry technique universally in all patients.

We have used a non-umbilical primary entry site, "Jain point", to avoid the retroperitoneal vessels, viscera, adhesion and bowel (VVAB) at the umbilicus, as a universal method in all routine cases and in abovementioned challenging situations.

\section{Method}

This is a large retrospective study of 7802 cases conducted from January 2011 to December 2020. The study period of almost a decade gave us the opportunity to improve and modify our technique in routine and increasingly challenging situations, and at the same time making the technique easy for beginners. The study was carried out at Vardhman Infertility \& Endoscopy Centre, India; which is a tertiary care centre for laparoscopic surgeries with an active fellowship program and many short-term trainees. Most of the laparoscopic entries are made by fellows and trainees, initially, under supervision of senior consultants. There is a short learning curve of $8-10$ cases, after that they are making entries on their own. Hence this technique is particularly feasible for beginners and novice endoscopist who have the fear of major retroperitoneal vessel injury and bowel and visceral injuries in the initial part of their careers.

We adopted the concept of universally using non -umbilical $5 \mathrm{~mm}$ first trocar entry in simplest to most complex cases in all body types, thin and obese, and all variety of pelvic pathology. Clinical situations with or without a previous surgery were entered by the newer $5 \mathrm{~mm}$ non-umbilical port the Jain point to assess the safety, feasibility, and to establish a new technique. All the laparoscopic surgeries where "Jain point" was used for first blind laparoscopic entry and then continued as main working port were included in the study.

\section{Surgical technique}

Jain point has an easily located prominent bony land mark in the sterile surgical field, i.e. the anterior superior iliac spine (ASIS). Surface marking of Jain point is that we first locate the ASIS then draw a (Fig. 1) vertical line $2.5 \mathrm{~cm}$ medial to ASIS, up to the level of umbilicus, then draw a horizontal line at the upper margin of umbilicus. And, where these two lines meet, that is the Jain point. This point lies at the level of 4th lumbar vertebrae roughly $10-13 \mathrm{~cm}$ lateral to the umbilicus depending on the patient's BMI and body

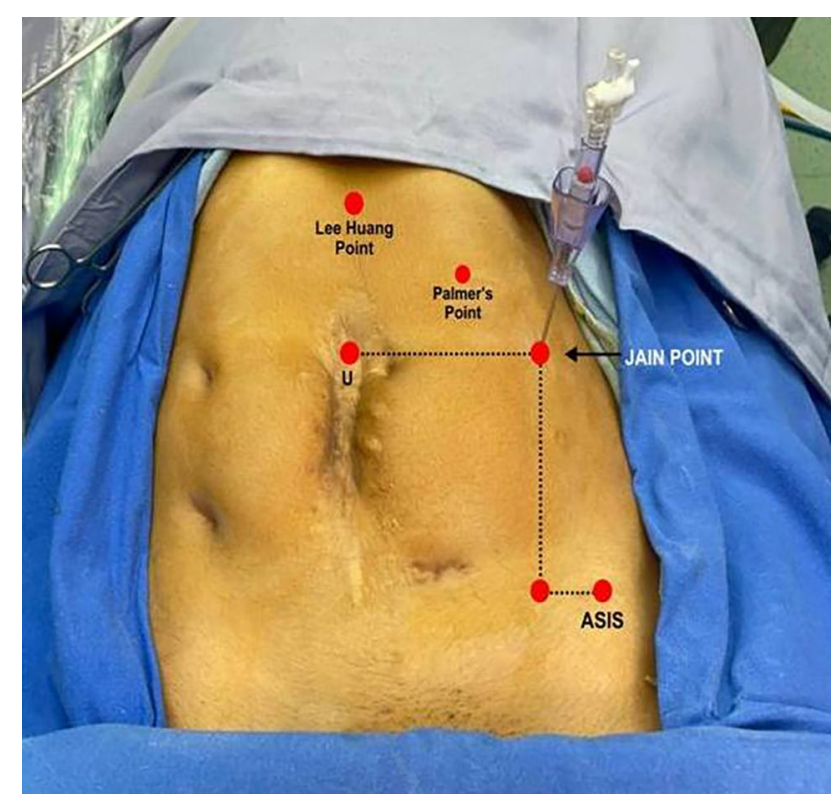

Fig. 1 Showing relative positions of all entry ports. Jain point is lowest and most lateral being 10 to $13 \mathrm{~cm}$ lateral to umbilicus at $\mathrm{L} 4$ level. It has a single very prominent bony landmark the ASIS. Palmers point is higher and more medial hence cannot be used as a working port 
types. The patient is laid in supine position, keeping the plane of the operation table parallel to the floor. A small nick of $2 \mathrm{~mm}$ is made just enough for Veress needle entry. Skin at Jain point is made taught between index and middle finger of left hand. Without lifting the abdominal wall, the Veress needle is inserted perpendicular to the abdominal wall, in a vertical direction irrespective of patient's BMI. We put a finger guard on the Veress needle according to the anticipated thickness of the abdominal wall. As the needle is passed, two distinct pops are heard. The first pop is heard, when the Veress needle passes through the external oblique aponeurosis. The second pop is heard when it pierces the fused aponeurosis of internal oblique and transverse abdominis muscle followed by resistance-free passage of needle in peritoneal cavity. The routine safety check of drop test and low initial Veress intra-peritoneal pressure test (LIVIP) [8] is done before starting $\mathrm{CO}_{2}$ insufflation. If high insufflation pressure is noticed, abdominal wall may be lifted to disengage the Veress needle tip from the omentum. With insufflation pressure of $25 \mathrm{~mm} \mathrm{Hg}$ and about three litres gas flown in the abdomen, a $5 \mathrm{~mm}$ trocar and cannula with open vent is inserted with screwing movement, through the Jain point. A zero degree $5 \mathrm{~mm}$ telescope is put into the abdomen through the $5 \mathrm{~mm}$ trocar. Thorough inspection of whole abdomen and pelvis is carried out and a $10 \mathrm{~mm}$ telescope is introduced under visual guidance (Fig. 2), at umbilicus or in upper abdomen according to the need of the case. In our technique, avoiding umbilicus as first blind entry point gives us safety against injury to VVAB (vessel, viscera, adhesions and bowel). (Fig. 3) The Jain point port is then used as the main ergonomic working port throughout the course of the surgery as also mentioned in the article by HT Sharp [1]. (Fig. 4) Being situated at the level of umbilicus, it can also be used in situations where Palmer's Point is contraindicated as in upper abdominal previous surgery scars, bloated stomach, large upper abdomen gastropancreatic masses, hepatosplenomegaly and portal hypertension.
Fig. 2 Optimizing the $10 \mathrm{~mm}$ port under the vision of $5 \mathrm{~mm}$ port inserted at the Jain point, to avoid dense periumblical adhesions in this case
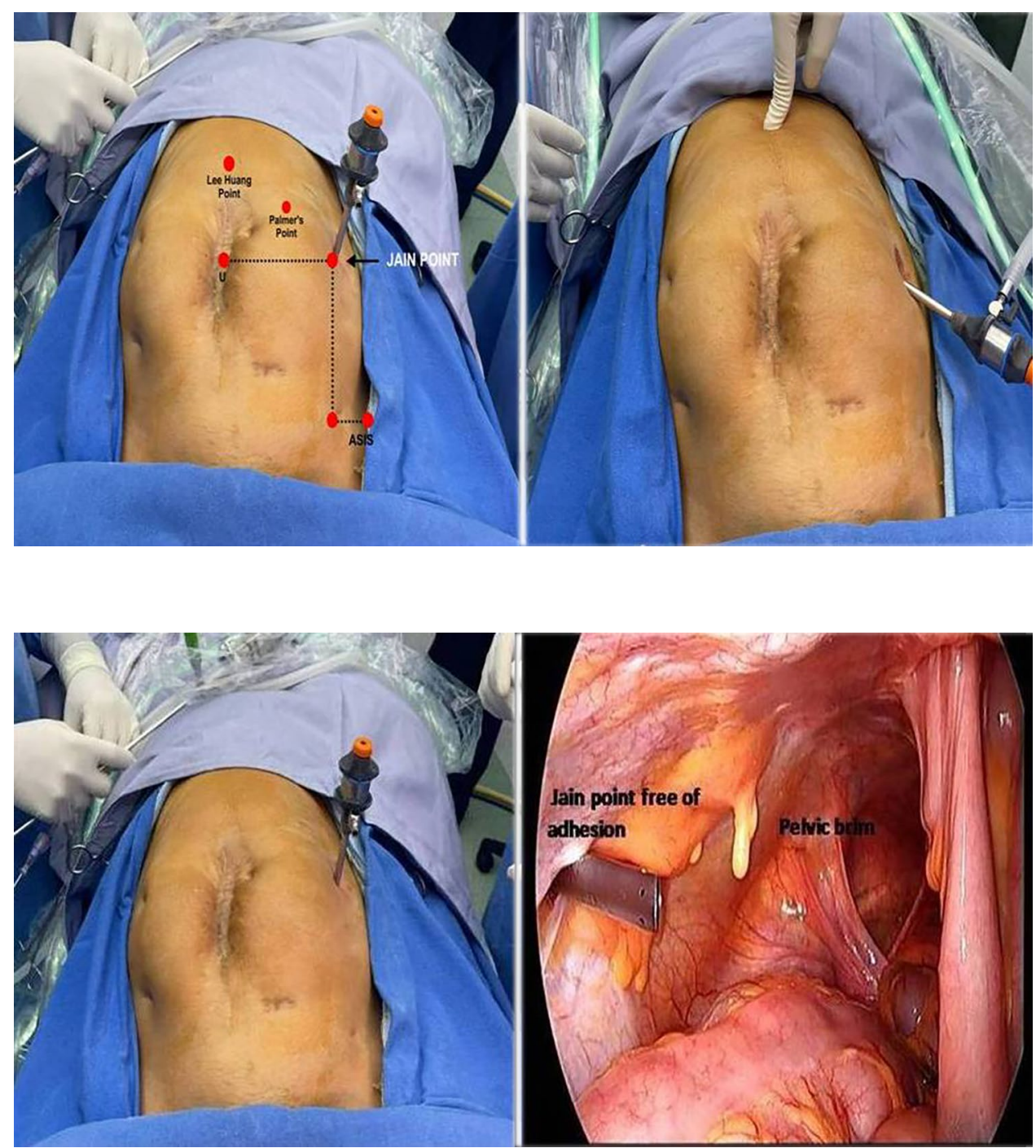

Fig. 3 Showing Jain Point port coming from adhesion free area 
Fig. 4 Jain Point port continues as the main ergonomic working port in due course of the surgery

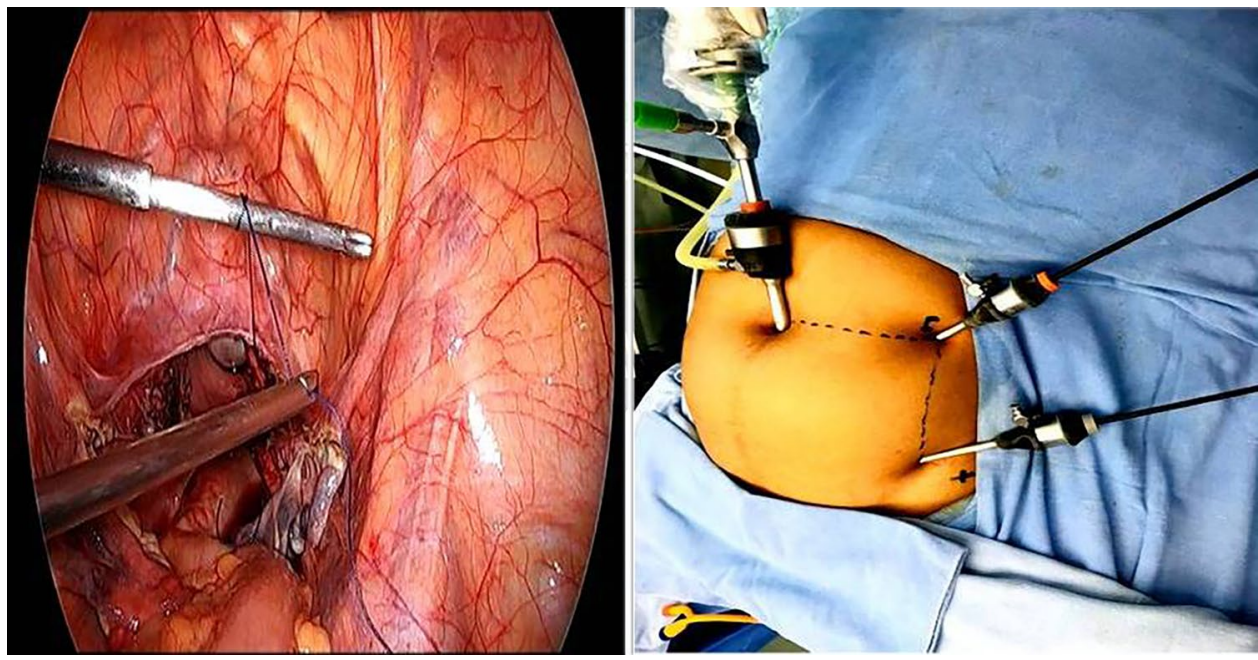

\section{Data collection and statistical analysis}

The data were collected from Vardhman Trauma \& Laparoscopy Centre Pvt. Ltd hospital's operation theatre records. To study the comprehensiveness of Jain point, patient's demographic profile like age, BMI, parity, number of previous surgeries, weight of solid masses, and type of laparoscopic surgeries performed and complications encountered during or after primary port insertion were recorded. The data analysis was done using the Statistical Package for Social Sciences (SPSS version 21). Continuous variables such as age and body mass index (BMI) were presented as mean \pm 2 $\mathrm{SD}$, whereas quantitative variables like parity and previous surgery status was presented as frequency, relative frequency and range, type of surgeries performed and entry related complications were presented as frequency and relative frequency.

\section{Results}

A total of 7802 laparoscopic surgeries were included in this study. The demographic data are summarised in Appendix Table 1. Types of surgeries performed are shown in Table 2. Weight of the solid masses removed is given in separate Table.3.

On average, the age of the patients was around 33 years. The BMI ranged from $12.66 \mathrm{~kg} / \mathrm{m}^{2}$ to $54.41 \mathrm{~kg} / \mathrm{m}^{2}$. Only half of the cases $(46.27 \%)$ belonged to normal BMI range whereas one-third of cases (34.52\%) were overweight. A prominent number of patients were obese $(12.72 \%)$ and morbidly obese (1.08\%), and the size of undernourished patients (5.37\%) was also noticeable. (Fig. 5) As per parity statistics, around 4085 women were nulliparous, and 3717 women were multiparous. Based on previous abdominal surgeries
Table 1 Demographic profile of patients who underwent laparoscopic surgeries. (January 2011 to December 2020)

\begin{tabular}{llll}
\hline Characteristics & Values & Median & Range \\
\hline Age $($ years $)$ & $32.79+15.2^{\mathrm{a}}$ & 31 & $8-76$ \\
BMI $\left(\mathrm{kg} / \mathrm{m}^{2}\right)$ & $25.30+9.52^{\mathrm{a}}$ & 24.90 & $12.66-54.41$ \\
$<18.5$ & $419(5.37)^{\mathrm{b}}$ & & \\
$18.5-24.99$ & $3610(46.27)^{\mathrm{b}}$ & & \\
$25-29.99$ & $2694(34.52)^{\mathrm{b}}$ & & \\
$30-39.99$ & $994(12.72)^{\mathrm{b}}$ & & \\
$>40$ & $85(1.08)^{\mathrm{b}}$ & & \\
Parity & & & \\
Nullipara & $4085(52.67)^{\mathrm{b}}$ & - & \\
Multipara & $3717(47.32)^{\mathrm{b}}$ & 2 & \\
Previous abdominal surgeries & & \\
No previous surgery & $5561(71.3)^{\mathrm{b}}$ & - & \\
Previous one surgery & $1744(22.5)^{\mathrm{b}}$ & - & - \\
Previous two surgeries & $371(4.6)^{\mathrm{b}}$ & - & $3-6$ \\
$\geq 3$ previous surgeries & $126(1.5)^{\mathrm{b}}$ & 3 \\
\hline
\end{tabular}

$B M I$ body mass index

${ }^{\mathrm{a}}$ Mean +2 standard deviation

${ }^{\mathrm{b}}$ Absolute number (percentage)

records, it is evident that in $71.27 \%$ women, no previous surgery was done. However, almost one-third of the cases (28.72\%) were with previous surgery, either laparoscopy or laparotomy.

The endoscopic surgeries performed at our institute ranged from as simple as infertility evaluation to as complex as deep infiltrating endometriosis, pelvic floor repair and large pelvic masses. It is noteworthy that no case was converted into open surgery, and no mortality was reported, in this study period.

Minor complications noticed were like subcutaneous and omental emphysema due to occasional undershoot and 
Table 2 Types of surgery performed

\begin{tabular}{|c|c|c|c|}
\hline S. N & $\begin{array}{l}\text { Types of surgery performed } \\
\text { (January } 2011 \text { to December 2020) }\end{array}$ & $\begin{array}{l}\text { Total number- } \\
7802\end{array}$ & $\begin{array}{l}\text { With } \\
\text { prev. } \\
\text { surgery- } \\
2241\end{array}$ \\
\hline 1 & TLH & 963 & 346 \\
\hline 2 & Myomectomy & 899 & 199 \\
\hline 3 & Adenomyomectomy & 96 & 35 \\
\hline \multirow[t]{5}{*}{4} & Endometriosis & & \\
\hline & Gr. III/IV endometriosis/DIE & 967 & 265 \\
\hline & Gr. I/II endometriosis & 444 & 141 \\
\hline & Scar endometriosis & 14 & 14 \\
\hline & Bladder endometriosis & 6 & 3 \\
\hline \multirow[t]{4}{*}{5} & Ovarian cystectomy & & \\
\hline & Ovarian cyst & 304 & 51 \\
\hline & Dermoid cyst & 97 & 24 \\
\hline & Post TLH ovarian cyst & 12 & 12 \\
\hline 6 & Pelvic floor repair & 146 & 43 \\
\hline 7 & Mullerian anomalies & 146 & 43 \\
\hline 8 & Ectopic & 333 & 121 \\
\hline 10 & Koch's & 1145 & 451 \\
\hline 11 & Tubal block & 533 & 200 \\
\hline 12 & Recanalization & 27 & 20 \\
\hline 13 & Vaginoplasty & 15 & 0 \\
\hline 14 & Burch colposuspension & 27 & 0 \\
\hline 15 & Para vaginal repair & 10 & 2 \\
\hline 16 & Presacral neurectomy & 15 & 1 \\
\hline 17 & Lap for pelvic pain & 97 & 58 \\
\hline 18 & 2nd look procedures & 121 & 121 \\
\hline 19 & Diagnostic laparoscopy infertility evaluations & 1372 & 86 \\
\hline 20 & Appendectomy & 6 & 2 \\
\hline 21 & Cholecystectomy & 2 & 1 \\
\hline 22 & Other & 5 & 2 \\
\hline
\end{tabular}

We are giving details of the procedures carried out and have given a separate table for weight of myomas and uteri
Table 3 Cases with solid masses (TLH \& myomectomy)

\begin{tabular}{llll}
\hline \multicolumn{2}{l}{ Cases with solid masses (TLH \& myomectomy) } & \multirow{2}{*}{ Total } \\
\cline { 1 - 3 } Weight of specimen (in g) & TLH & Myomectomy & \\
\hline Less than $300 \mathrm{~g}$ & 669 & 488 & 1157 \\
$300-<500 \mathrm{~g}$ & 126 & 188 & 314 \\
$500-<1000 \mathrm{~g}$ & 112 & 147 & 259 \\
$1000-<1500 \mathrm{~g}$ & 33 & 37 & 70 \\
$1500-<2000 \mathrm{~g}$ & 8 & 19 & 27 \\
$\geq 2000 \mathrm{~g}$ & 13 & 20 & 33 \\
Total & 961 & 899 & 1860 \\
\hline
\end{tabular}

overshoot of veress needle which is quickly detected by higher intra-abdominal pressure in first $10 \mathrm{~s}$ (LIVIP) [8] and occasionally failed entry that too in the beginning of learning curve, which settles within few procedures.
There was no major vessels injury. One bowel injury was seen in a case of advanced Koch's, where small bowel injury was noticed in a case of Koch's abdomen with previous history of open surgery by a transverse scar at the level of umbilicus. We preoperatively had a very high index of suspicion of adhesions and got an MRI done which showed no bowel beneath the scar, and then we took her for laparoscopy. Needless to say, it was not a good reporting as the first $5 \mathrm{~mm}$ trocar went straight into the adherent loop of bowel in the frozen pelvis. The incision at the trocar site was enlarged to $3 \mathrm{~cm}$ and the bowel injury repaired. The patient was nil orally till bowel sounds returned and patient was discharged on day four post-operatively without any sequelae. 


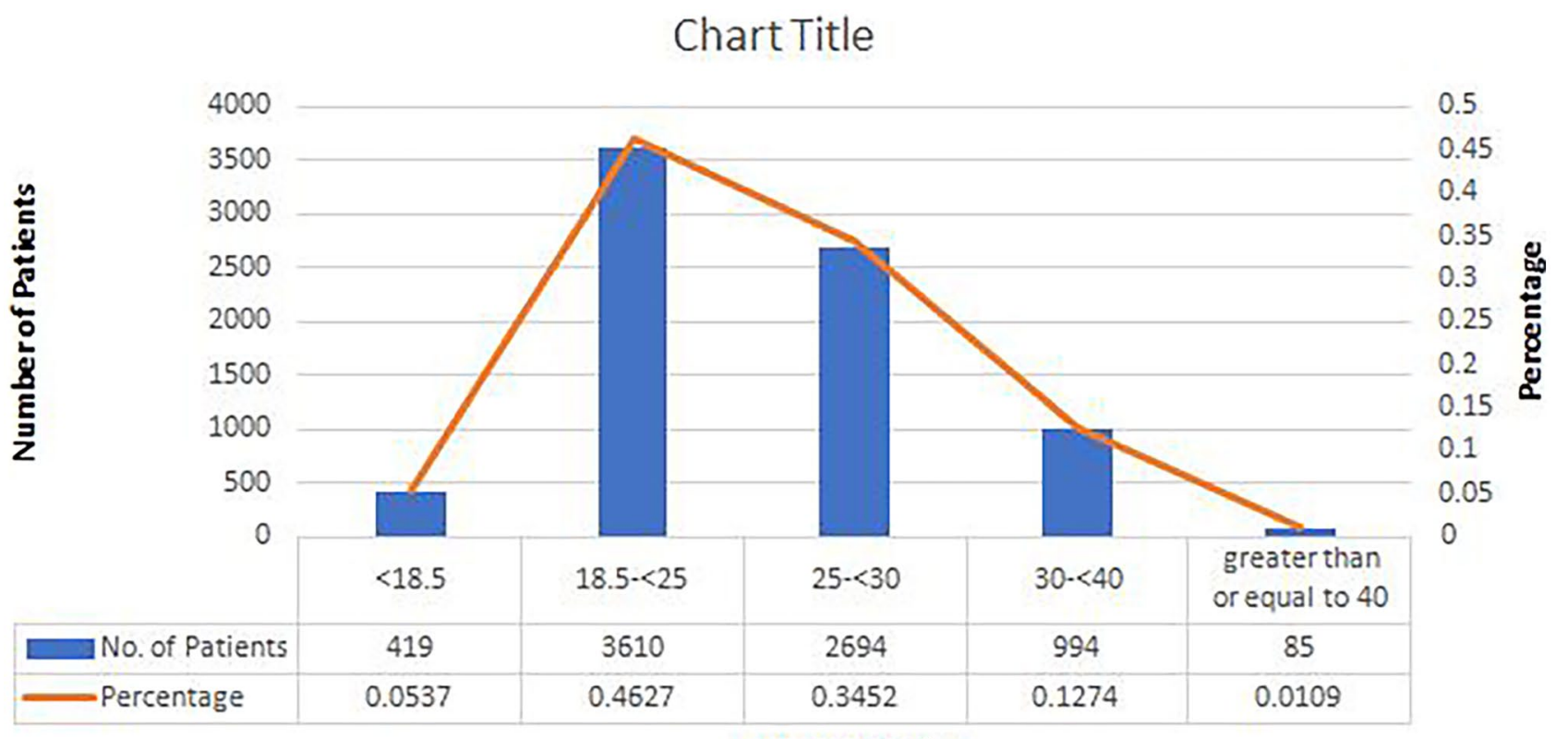

Fig. 5 BMI profile of Patients

\section{Discussion}

This study presents a novel, non-umbilical, first blind $5 \mathrm{~mm}$ entry port through Jain point in large number of different types of laparoscopic surgeries in a routine manner with the aim of avoiding catastrophic complications related to entry. We improvised the first blind entry by introducing a new entry point which is situated $10-13 \mathrm{~cm}$ away from the umbilicus, thus minimizing chances of injury to the great vessels. Laparoscopic entry was performed in 7802 surgeries without any significant complications. The mean BMI in our study was $25.30 \mathrm{~kg} / \mathrm{m}^{2}$. Individuals with extreme body habitus have variable umbilical-aortic bifurcation relationship, thus impose technical challenges in blind entry through the umbilicus $[9,10]$. In our study, $4192(53.72 \%)$ cases were operated with abnormal BMI i.e. either low BMI $(<18.5 \mathrm{~kg} /$ $\mathrm{m}^{2}$ ) or high BMI $\left(>25 \mathrm{~kg} / \mathrm{m}^{2}\right)$. With supine horizontal operation table, the long veress needle can be inserted through the Jain point in obese patients, perpendicular to the horizontal plane safely. There is no need to change the direction of needle during insertion. In thin patients due to very good muscle tone, the entry pops were very easily identified and entry was found to be easy. It is very simple way to avoid umbilicus and major retroperitoneal vessels which could be just $1.5 \mathrm{~cm}$ away in thin patients. We published our experience in thin patients [11]. For the same reason, it is useful in situations of lax abdominal wall. The technique of not lifting the abdominal wall, avoids the jagged tracks and undue pressure application over the abdomen, which may cause sudden overshooting of the veress needle.
Previous surgeries often lead to potential risk of damage to the bowel, omentum and viscera through umbilical site entry due to unforeseen adhesions [12]. We operated 2241 cases with history of previous one to a maximum of previous six surgeries and avoided encountering midline adhesions. The anatomical location of Jain point makes it free of adhesions [13-15]. If we look at the peritoneal location of viscera, the kidney and spleen come maximum upto $\mathrm{T} 10-\mathrm{L} 1$ level, whereas at Jain point, we are at L4 level. Lower down the sigmoid colon adheres to the pelvic brim, leaving a large nascent area free of adhesions on the left side which is used to make the Jain point entry at para-umbilical position. We have already published our experience of Jain point entry in 624 patients with previous abdominal surgeries and found this area on left side to be free of adhesions with no significant entry-related complications. It is applicable in low Pfannenstiel incision, midline vertical or paramedian incision. Jain point is especially a boon for upper abdomen scars [14] where various other non-umbilical entry points like Palmer's point [16, 17], left ninth intercostal space point [18] and Lee Huang point [19-21], are contraindicated. Their use is also contraindicated in hepatosplenomegaly, portal hypertension, history of previous upper abdomen surgery and in patients with full stomach due to faulty nasogastric tube placement [22]. Here, Jain point scores over all other entry ports, as it lies in mid abdomen and can be used in all contraindications of upper abdomen entry. In abdominogenital Koch's, lot of bowel and other dense adhesions exist between liver and diaphragm in upper abdomen making upper quadrant 
entry risky by the Palmers or Lee Huang ports [23-31]. In our series there were 1145 cases of Koch's abdomen where the primary entry is very challenging. Jain point entry can be made in presence of umbilical hernia and previous mesh hernia repairs. We had operated 11 patients with previous history of mesh hernia repair, in whom the size of the mesh was obtained from the records of previous surgery and a safe abdominal entry was done using Jain point. If we compare all existing entry points, Hasson's open technique has been undoubtedly the best amongst the available techniques till date [32]. However, a recent update on laparoscopic entries in up-to-date opinioned that Hasson may not be the safest $[33,34]$. It importantly cannot avoid the type II bowel adhesions where bowel loops are densely stuck to the anterior abdominal wall [35].

In patients where we anticipated dense adhesions on the left side of the abdomen as in previous colostomy scars, drains and colon pull through, we used mirror image of Jain point from the right side. Clearly Palmers point cannot be used from right side of abdomen due to heightened risk of liver injury. This application of Jain point from right side has been used by general surgeons and urologists [36]. Palmers and Lee Huang points being higher in position cannot be used as a working port especially in pelvic surgeries. Jain point being lower in position at L4 level can be safely used in all the above situations and becomes an ergonomic working port in due course of the surgery. Mulayam et al. have reported direct trocar entry from the Jain point [37]. Mohapatra and Bhusan [38] have also reported the benefit of the left lateral port as the main working port as well as the entry port, indicating dual benefit with good ergonomics. In a recent article "Clinical Perspective Concerning Abdominal Entry Techniques" published in JMIG (Journal of Minimally Invasive Surgery), Goodman L, et al. have also illustrated our Jain point as one of the abdominal entry ports [39].

The major complication rate seen in our study was restricted to one bowel injury in a case of complex advanced genital Koch's, with previous laparotomy which involved injury to the small intestines. There was no major vessel injury. The incidence in our series is lower than that seen with other entry points. A Dutch study involving 51,559 laparoscopic surgeries by closed-entry technique found an average entry related complication rate of $0.044 \%$ and $0.031 \%$ for visceral and vascular lesions, respectively [40]. We found no case of major retroperitoneal vessel injury or hematoma. Ours being a training institute, with active fellowship programs, the veress needle insertion is carried out by trainees, fellows and consultants. During transition from the technique of umbilical entry, to which trainees are used to, some prepertioneal and omental insufflation and occasional failed entries are seen in initial cases. We have realised that there is a short learning curve of few procedures. Once the rationale and methodology of the technique is well understood, there is a steep fall in such incidences. Every trainee and fellow has welcomed the routine use of non-umbilical first blind entry as it allays anxieties related to first blind umbilical entry port which has potential of sudden catastrophic vessel or bowel injury and they are carrying forward this technique further in their careers.

There is also experience of Jain point usage among other specialists of laparoscopic surgeries. Our unit is a primarily gynaecological unit but we have cases where gall bladder and hernia repairs are done by general surgeons along with TLH or other gynae surgeries. They have used Jain point in a likewise manner. We have demonstrated Jain point in several live surgery workshops and conferences done for the associations like SELSI (Society for Endoscopic and Laparoscopic Surgeons of India) and AMASI (Association of Minimal Access Surgeons of India) which have membership of gynaecologists, urologists, general surgeons and bariatric surgeons. We proposed Jain point as an alternative port when the first three options (umbilicus, Palmer's point and Lee-Huang point) are not viable. Moreover, Jain point port which is in mid abdomen can be used later on in surgery as the main working port. This feature is in stark contrast to Palmers point, which becomes redundant after initial entry [1] after our demonstration during live surgeries and lectures this paraumbilical port has been accepted, advocated and widely used by several general surgeons as well as urologists in their clinical practice. They have used it in cases wherever they deemed fit in previously scarred abdomen. This a limitation that, at this time, there are no literature reports of Jain point usage by general surgeons.

Also, our study is not without limitations. Though we have a large case series and study period of 10 years but it is retrospective in nature. It needs more multi-centre randomized control trials to give more data about its safe usage.

\section{Conclusion}

Our large series of 7802 patients entered by Jain point as first blind entry proposes that Jain point is a novel, safe $5 \mathrm{~mm}$ non-umbilical alternate entry point for laparoscopic first blind entry. It has a readily available fixed bony landmark, the ASIS, in the sterile surgical field making the surface marking easy and accurate. It is versatile and can be used in patients of different ranges of BMI, from simple to complex cases, large masses and cases with previous surgeries. After making initial first blind entry it continues to be used as a main ergonomic working port. We are routinely making non-umbilical entry by Jain point, a new concept aimed at reducing entry related injuries to major retro peritoneal 
vessels, viscera, adhesions and bowel (VVAB) which could lie under the umbilicus.

\section{Declarations}

\section{Conflict of interest None.}

Ethics approval and consent to participate This paper is the description of a technique that uses a different anatomical approach for an established procedure of blind port insertion in laparoscopic surgeries and does not come under World Medical Association Declaration of Helsinki definition of human experimentation. Still, the procedure and relevant risk involved was presented and discussed in our institution's review and audit board meeting. The board agreed upon the safety aspect of the technique and concluded that since it is a retrospective study and does not disclose the identity of the patient, it does not require ethical committee approval. It was believed that this technique is undertaken in the best interest of the patients and does not violates Indian Council of Medical Research ethical guidelines (2017).

Consent for publication All the authors consent for publication of this manuscript. We have been taking the consent of patients routinely along with the consent for surgery regarding the publication as this is a teaching institute as well. Patients were assured that their identity will not be disclosed. The consent has been taken regarding availablility of details and photos on the internet but the personal details will not be disclosed and will be treated confidentially. The images used in this paper do not disclose details of individuals.

Open Access This article is licensed under a Creative Commons Attribution 4.0 International License, which permits use, sharing, adaptation, distribution and reproduction in any medium or format, as long as you give appropriate credit to the original author(s) and the source, provide a link to the Creative Commons licence, and indicate if changes were made. The images or other third party material in this article are included in the article's Creative Commons licence, unless indicated otherwise in a credit line to the material. If material is not included in the article's Creative Commons licence and your intended use is not permitted by statutory regulation or exceeds the permitted use, you will need to obtain permission directly from the copyright holder. To view a copy of this licence, visit http://creativecommons.org/licenses/by/4.0/.

\section{References}

1. Sharp HT(2019) Overview of gynecologic laparoscopic surgery and non-umbilical entry sites. In: Falcone T (ed) UpToDate, p 10

2. Alkatout I (2017) Complications of laparoscopy in connection with entry techniques. J Gynecol Surg 33(3):81-91

3. Attwell L, Rosen S, Upadhyay B, Gogalniceanu P (2015) The umbilicus: a reliable surface landmark for the aortic bifurcation? Surg Radiol Anat 37:1239-1242

4. Ellis H (1998) The magnitude of adhesion related problems. Ann Chir Gynaecol 87:9-11

5. Liakakos T, Thomakos N, Fine PM, Dervenis C, Young RL (2001) Peritoneal adhesions: etiology, pathophysiology, and clinical significance. Recent advances in prevention and management. Dig Surg 18:260-273 (PubMed)
6. Jansen FW, Kapiteyn K, Trimbos-Kemper T, Hermans J, Trimbos JB (1997) Complications of laparoscopy: a prospective multicentre observational study. Br J Obstet Gynecol 104:595-600

7. RCOG (2008) Green-top guideline: preventing entry-related gynaecological laparoscopic injuries. Royal College of Obstetricians and Gynaecologists, London, p 49

8. Vilos GA (2006) The ABCs of a safer laparoscopic entry. J Minim Invasive Gynecol 13:249-251

9. Pelosi MA III, Pelosi MA (1998) Alignment of the umbilical axis: an effective maneuver for laparoscopic entry in the obese patient. Obstet Gynecol 92:869-872

10. Hurd WW, Bude RO, DeLancey JO et al (1992) The relationship of the umbilicus to the aortic bifurcation: implications for laparoscopic technique. Obstet Gynecol 80(1):48-51

11. Jain N, Singh S, Mandal KK et al (2020) A retrospective study of a novel non-umbilical laparoscopic entry port in thin patients—Jain point. Gynecol Surg 17:13. https://doi.org/10.1186/ s10397-020-01080-5

12. Batemen BG, Kolp LA, Hoeger K (1996) Complications of laparoscopy - operative or diagnostic. Fertil Steril 66:30-35

13. Jain N, Sareen S, Kanawa S, Jain V, Gupta S, Mann S (2016) Jain point: a new safe portal for laparoscopic entry in previous surgery cases. J Hum Reprod Sci 9:9-17

14. Jain N, Jain V, Aggarwal C (2019) Left lateral port: safe laparoscopic port entry in previous large upper abdomen laparotomy scar. J Minim Invasive Gynecol 26(5):973-976. https://doi.org/ 10.1016/j.jmig.2018.10.017

15 Jain N (2018) Jain point: a new safe portal for laparoscopic entry in previous surgery cases. J Minim Invasive Gynecol 25(7):S256-S257

16. Davis CJ (2005) Prospective use of Palmer's point entry for therapeutic laparoscopy in women with previous abdominal surgery. $\mathrm{J}$ Minimal Invasive Gynecol 12(5 Suppl):65

17. Palmer R (1974) Safety in laparoscopy. J Reprod Med 13:1-5

18. Agarwala B, Liu CY (2005) Safe entry techniques during laparoscopy: left upper quadrant entry using the ninth intercostal space- a review of 918 procedures. J minim Invasive Gynecol 12(1):55-61

19. Lee CL, Huang KG, Jain S, Wang CJ, Yen CF, Soong YK (2001) A new portal for gynecologic laparoscopy. J Am Assoc Gynecol Laparosc 8:147-150

20. Lee CL, Huang KG (2002) Total laparoscopic radical hysterectomy using Lee-Huang portal and McCartney transvaginal tube. J Am Assoc Gynecol Laparosc 9:536-540

21. Huang KG, Lee CL (2007) The four-trocar method for performing laparoscopically-assisted vaginal hysterectomy on large uteri. J Minim Invasive Gynecol 14:265-266

22. Jain N, Jain V (2020) Limitations and contraindications of Palmer's point. In: Jain N (ed) Non-umbilical laparoscopic entry ports, 1st edn. Jaypee Brothers Medical Publishers, New Delhi, pp 76-84

23. Gupta N, Sharma JB, Mittal S et al (2007) Genital tuberculosis in Indian infertility patients. Int J Gynecol Obstet 97(2):135-138

24. Sharma JB, Pushparaj M, Gupta N et al (2008) Genital tuberculosis: an important cause of Ashermans' syndrome in India. Arch Gynecol Obstet 277:37-41

25. World Health Organization (1994) TB: a global emergency, WHO report on the TB epidemic. World Health Organization, Geneva

26. Dye C, Watt CJ, Bleed DM et al (2005) Evolution of tuberculosis control and prospects for reducing tuberculosis incidence, prevalence and deaths globally. JAMA 293:2790-2793

27. Sutherland AM (1983) The changing pattern of tuberculosis of the female genital tract: a thirty-year survey. Arch Gynaecol 234:95-101

28. Sharma JB, Roy KK, Gupta N et al (2007) High prevalence of Fitz-Hugh-Curtis syndrome in genital tuberculosis. Int J Gynecol Obstet 99:62-63 
29. Sharma JB (2008) Tuberculosis and obstetric and gynecological practice. In: Studd J, Tan SL, Chervenak FA (eds) Progress in obstetric and gynaecology. Elsevier, Philadephia, pp 395-427

30. Sharma JB, Roy KK, Pushparaj M et al (2008) Laparoscopic finding in female genital tuberculosis. Arch Gynecol Obstet 278:359-364

31. Sharma JB, Mohanraj P, Roy KK et al (2010) Increased complication rates associated with laparoscopic surgery among patients with genital tuberculosis. Int J Gynecol Obstet 109:242-244

32. Hasson HM (1999) Open laparoscopy as a method of access in laparoscopic surgery. Gynaecol Endosc 8:353-362

33. Hasson H (1971) A modified instrument and method laparoscopy. Am J Obstet Gynecol 110:886-887

34. Hasson HM, Rotman C, Rana N, Kumari NA (2000) Open laparoscopy: 29-year experience. Obstet Gynecol 96:763-766

35. Krishnakumar S, Tambe P (2009) Entry complications in laparoscopic surgery. J Gynecol Endosc Surg 1:4

36. Gupta S. Jain point in the practice of general surgery. In: Jain $\mathrm{N}$ (ed) Non-umbilical laparoscopic entry ports: 2020. Jaypee brothers medical publishers, New Delhi, pp 254-273
37 Mulayam B, Aksoy O (2020) Direct trocar entry from left lateral port (Jain point) in a case with previous surgeries. J Gynecol Surg. https://doi.org/10.1089/gyn.2019.0077

38. Mohapatra GSS, Bhusan B (2017) Comparative study of different entry sites in laparoscopic surgery: which is safest? IOSR J Dent Med Sci 16:64-66

39 Goodman L et al (2020) Clinical perspective concerning abdominal entry techniques. J Minim Invasive Surg. https://doi.org/10. 1016/j.jmig.2020.07.010

40. Jansen FW, Kolkman W, Bakkum EA, de Kroon CD, TrimbosKemper TC, Trimbos JB (2004) Complications of laparoscopy: an inquiry about closed- versus open-entry technique. Am J Obstet Gynecol 190:634-638

Publisher's Note Springer Nature remains neutral with regard to jurisdictional claims in published maps and institutional affiliations. 